\title{
Immunologic Phenotype of a Child With the MEHMO Syndrome
}

\section{Ivana TROCHANOVÁ ${ }^{1}$, Daniela STANÍKOVÁ ${ }^{1,2}$, Martina ŠKOPKOVÁ ${ }^{2}$, Klaudia HAŠTOVÁ ${ }^{3}$, Daniela GAŠPERÍKOVÁ ${ }^{2}$, Juraj STANÍK ${ }^{1,2}$, Peter ČIŽNÁR ${ }^{1}$}

${ }^{1}$ Department of Pediatrics, Medical Faculty of Comenius University and National Institute of Children's Diseases, Bratislava, Slovak Republic, ${ }^{2}$ DIABGENE \& Laboratory of Metabolic Disorders, Institute of Experimental Endocrinology, Biomedical Research Center, Slovak Academy of Sciences, Bratislava, Slovak Republic, ${ }^{3}$ Office of General Practitioner for Children and Adolescents, Bratislava, Slovak Republic

Received May 4, 2020

Accepted August 25, 2020

Epub Ahead of Print September 9, 2020
Primary immunodeficiencies (PID) are a heterogeneous group of inborn disorders characterized by dysfunction of immune system or absent function in one or more components of the immune system (McCusker and Warrington 2011). PID are rare diseases with an estimated prevalence of 1 in 1200 live births (Boyle and Buckley 2007, Modell et al. 2014). Most of them are genetic disorders with onset in early childhood, usually during the first year of life with recurrent or persistent infections (otitis, sinus infections, pneumonia, skin abscesses), developmental delay, failure to thrive, and predisposition for autoimmune diseases and tumors (Vozeh 2018). Early diagnosis and treatment are critical for preventing severe complications and early mortality (Shehata et al. 2010). PID are often associated with various syndromes.

MEHMO syndrome is a rare X-linked disorder characterized by mental retardation, epilepsy, hypogenitalism, microcephaly and obesity (Steinmuller et al. 1998, Skopkova et al. 2017). It is caused by the Ile465Serfs mutation in the EIF2S3 gene encoding eukaryotic translation initiation factor 2 (eIF2) $\gamma$ subunit, while missense mutations cause less severe clinical picture (Skopkova et al. 2017, Young-Baird et al. 2020). Decreased initiation of proteosynthesis is one of the cellular responses to endoplasmic reticulum stress and triggers further actions that can eventually lead to apoptosis (Pavitt and Ron 2012). Therefore, impairment

PHYSIOLOGICAL RESEARCH • ISSN 1802-9973 (online) 
of eIF2 has the most important impact on cells with high protein synthesis rate or cells requiring stringent proteosynthesis regulation. This is supported by the observed deficiency of the EIF $2 S 3$ mutation carrying patients in peptide hormones (Stanik et al. 2018). Therefore we hypothesized that protein synthesis defect could influence serum immunoglobulin levels or other protein components of naive and adaptive immune response and cause the phenotype of primary immunodeficiency in the MEHMO patients. Here we describe the immunologic phenotype in a male proband with MEHMO and immunoglobulin therapy outcomes.

We refer on previously described proband of Slovak origin (Skopkova et al. 2017, Stanik et al. 2018) with MEHMO syndrome caused by the causal Ile465Serfs mutation in the EIF2S3 gene. Blood count, immunoglobulins levels and CRP were measured in the local labs by standardized methods. Flow cytometry was realized by Navios EX flow cytometer (Beckman Coulter) and immunoglobulins by Cobas C501 analyzer (Roche). By the retrospective analysis in proband we evaluated the frequency of febrile infections, respiratory tract infections, frequency of antibiotic therapy and serum immunoglobulin levels according to the immunoglobulin treatment (Gammanorm ${ }^{\circledR} \quad 165 \mathrm{mg} / \mathrm{ml}$ solution for subcutaneous injection, Octapharma, Belgium). Febrile infection was defined as an increase in body temperature with an increase of laboratory inflammatory markers (C-reactive protein, leukocytosis). Respiratory tract infection was defined as symptoms of rhinitis, bronchitis, cough or dyspnea.

Statistical analyses were performed with GraphPad Prism v7.0 software (GraphPad Software, San Diego, USA) and SPSSv25 software (IBM, NY, USA). Numeric data are displayed as mean \pm SD. Poisson regression models were used to assess differences in incidence rates for acute infections and antibiotic use. Regression model included data since the $1^{\text {st }}$ year of life until one month after stopping the therapy with immunoglobulins at the age of 9.2 years. As dependent variable was selected sequentially number of acute infections, number of respiratory infections, number of antibiotics, and number of systemic antibiotics used during the time of observation. Counts were calculated as whole numbers per year, and weighted for the time period shorter than 1 year. Immunoglobulin therapy (yes, no) was the only factor included to the model. $\mathrm{P}$ values less than 0.05 were considered as statistically significant.

All steps of this study were approved by the
Ethics Committee of National Institute of Children's Diseases in Bratislava, Slovakia. Written informed consent was signed by parents of the proband.

The results of the blood counts, CRP levels, flow cytometry and immunoglobulins of the patient (MEHMO syndrome with frequent acute infections) are summarized in Table 1. In our proband, the diagnosis of MEHMO was made at the age of 10 months. Currently, he is a 9-yearold boy. He was vaccinated with the first dose of the diphtheria-tetanus-pertussis vaccine, however, the vaccination was discontinued after epilepsy onset. The patient had the first upper respiratory tract infection at the age of 5 months. Subsequently, he was repeatedly hospitalized for pneumonia and urinary tract infections during the infant period and he required treatment with antibiotics. During the follow-up the patient was treated predominantly by a systemic antibiotic therapy of which $29 \%$ was beta-lactam antibiotics, penicillins, $29 \%$ cefalosporins, $17 \%$ chinolons, $16 \%$ macrolides a $9 \%$ of sulfonamides.

During the follow-up (Table 1), the neutrophil counts and total lymphocyte counts were within the normal age-adjusted reference range. $\mathrm{T}$ and $\mathrm{NK}$ cell populations, including $\mathrm{CD} 4+$ and $\mathrm{CD} 8+\mathrm{T}$-cell subpopulations and naive CD4+ $\mathrm{T}$ cells corresponded to the patient's age as well. B cells, though initially normal, tended to decrease. Serum immunoglobulin M (IgM) and immunoglobulins $\mathrm{G}$ ( $\mathrm{IgG}$ ) levels were within the physiological range during the first 5 years of his life (Table 1), however, immunoglobulin A (IgA) levels remained very low during the whole monitored period. Patient has not been regularly vaccinated.

In regard to frequent infections, we initiated subcutaneous immunoglobulin therapy with a dose of $200 \mathrm{mg} / \mathrm{kg} /$ every 2 weeks at the age of 5.4 years. During the treatment, we have achieved supra-physiological serum levels of IgG (Fig. 1). The incidence of acute infections per year was lower over the 3.8 years on the treatment compared with the time period since the $1^{\text {st }}$ year of life until the therapy start $(10.36 \pm 2.96$ vs. $5.89 \pm$ 2.90 acute infections per year without and on immunoglobulin treatment, in the Poisson regression was the incidence reduction by $54.5 \%, \mathrm{p}=0.017$ ). Similar results were obtained in reduction of frequency of respiratory tract infections $(8.50 \pm 3.58$ vs. $4.68 \pm$ 2.93 respiratory infections per year, incidence reduction by $51.4 \%, \mathrm{p}=0.018$ ), and systemic antibiotics use $(7.45 \pm 2.82$ vs. $4.00 \pm 1.85$ systemic antibiotics per year, rate reduction by $50.0 \%, \mathrm{p}=0.024)$. We observed the 
same trend in reduction of frequency of episodes of antibiotic treatment $(8.59 \pm 2.96$ vs. $5.47 \pm 2.96$ antibiotic therapies per year, rate reduction by $59.4 \%, p=0.053$ ) however, the differences were not significant. In Figure 1 are the rates displayed per month, as some time periods were shorter than 1 year.

Table 1. Laboratory parameters of immune system in boy with MEHMO syndrome.

\begin{tabular}{|c|c|c|c|c|c|c|c|c|c|c|}
\hline \multirow{2}{*}{$\begin{array}{l}\text { Parameter } \\
\text { Age (years) }\end{array}$} & \multicolumn{10}{|c|}{ Proband } \\
\hline & 0.5 & 1 & 2 & 3 & 4 & 5 & 6 & 7 & 8 & 9 \\
\hline Weight (kg) & 4.32 & 7.85 & 11.89 & 13.8 & 16 & 15.3 & 16.5 & 16.7 & 19.5 & 22.7 \\
\hline Height (cm) & 55 & 69 & & 87 & 87 & 88 & 90 & 90 & 105 & 105 \\
\hline $\begin{array}{l}\text { Leukocytes }\left(10^{9} / l\right) \\
(N: 4-10)\end{array}$ & 7.10 & 12.80 & 15.10 & 7.75 & 7.30 & 9.10 & 12.90 & 7.94 & 9.00 & 8.39 \\
\hline $\begin{array}{l}\text { Lymphocytes }\left(10^{9} / l\right) \\
(N: 1.5-7.0)\end{array}$ & 5.00 & 7.78 & 5.41 & 4.30 & 1.80 & 3.20 & 3.65 & 4.14 & 4.70 & 2.89 \\
\hline $\begin{array}{l}\text { Neutrophils }\left(10^{9} / \mathrm{l}\right) \\
(N: 1.8-8)\end{array}$ & & 3.53 & 8.85 & 2.63 & 4.80 & 5.30 & 8.31 & 2.96 & 3.80 & 4.55 \\
\hline $\begin{array}{l}\text { Hemoglobin }(\mathrm{g} / \mathrm{dl}) \\
(\mathrm{N}: 11.5-15.5)\end{array}$ & 9.60 & 13.80 & 11.6 & 14.00 & 12.2 & 13.6 & 12.3 & 11.1 & 10.1 & 10.1 \\
\hline $\begin{array}{l}\operatorname{Ig} G(g / l) \\
(N: 6.00-13.00)\end{array}$ & & 4.10 & 8.35 & 7.98 & 10.40 & 12.60 & 16.50 & 16.00 & 17.96 & 18.21 \\
\hline $\begin{array}{l}\operatorname{Ig} A(g / l) \\
(N: 0.51-2.97)\end{array}$ & & 0.32 & 0.28 & 0.31 & 0.33 & 0.13 & 0.09 & 0.05 & 0.05 & 0.05 \\
\hline $\begin{array}{l}\operatorname{IgM}(g / l) \\
(N: 0.40-1.50)\end{array}$ & & 0.31 & 0.59 & 0.61 & 0.63 & 1.00 & 0.93 & 0.83 & 1.03 & 1.14 \\
\hline $\begin{array}{l}C 3(g / l) \\
(N: 0.88-2.01)\end{array}$ & & & 1.60 & & & & 1.50 & 1.30 & 1.50 & 1.45 \\
\hline $\begin{array}{l}C 4(g / l) \\
(N: 0.16-0.47)\end{array}$ & & & 0.31 & & & & 0.20 & 0.16 & 0.17 & 0.21 \\
\hline $\begin{array}{l}C D 3\left(10^{9} / l\right) \\
(N: 1.80-3.00)\end{array}$ & & & & & 3.20 & & & & 2.50 & 1.73 \\
\hline $\begin{array}{l}C D 19\left(10^{9} / l\right) \\
(N: 0.70-1.30)\end{array}$ & & & & & 0.90 & & & & 0.60 & 0.61 \\
\hline $\begin{array}{l}C D 16+56\left(10^{9} / l\right. \\
(N: 0.20-0.60)\end{array}$ & & & & & 0.70 & & & & 1.02 & 0.23 \\
\hline $\begin{array}{l}C D 3+C D 4+\left(10^{9} / l\right. \\
(N: 1.00-1.80)\end{array}$ & & & & & 1.50 & & & & 1.40 & 0.97 \\
\hline $\begin{array}{l}C D 3+C D 8+\left(10^{9} / l\right. \\
(N: 0.80-1.50)\end{array}$ & & & & & 1.30 & & & & 0.96 & 0.59 \\
\hline $\begin{array}{l}C R P(m g / l) \\
(N:<5)\end{array}$ & 2.60 & 0.00 & 3.90 & 3.00 & 47.00 & 28.70 & 5.00 & 4.50 & 37.00 & 5.70 \\
\hline $\begin{array}{l}\text { Cholesterol (mmol/l) } \\
(\mathrm{N}: 3.21-4.80)\end{array}$ & 4.83 & & 9.49 & 9.61 & 9.31 & 8.14 & 6.00 & 5.49 & 6.36 & 6.11 \\
\hline $\begin{array}{l}\text { Triacylglycerol (mmol/l) } \\
(\mathrm{N}: 0.0-1.30)\end{array}$ & & & 6.05 & 6.36 & 6.96 & 2.84 & 3.15 & 3.77 & 2.44 & 1.98 \\
\hline
\end{tabular}



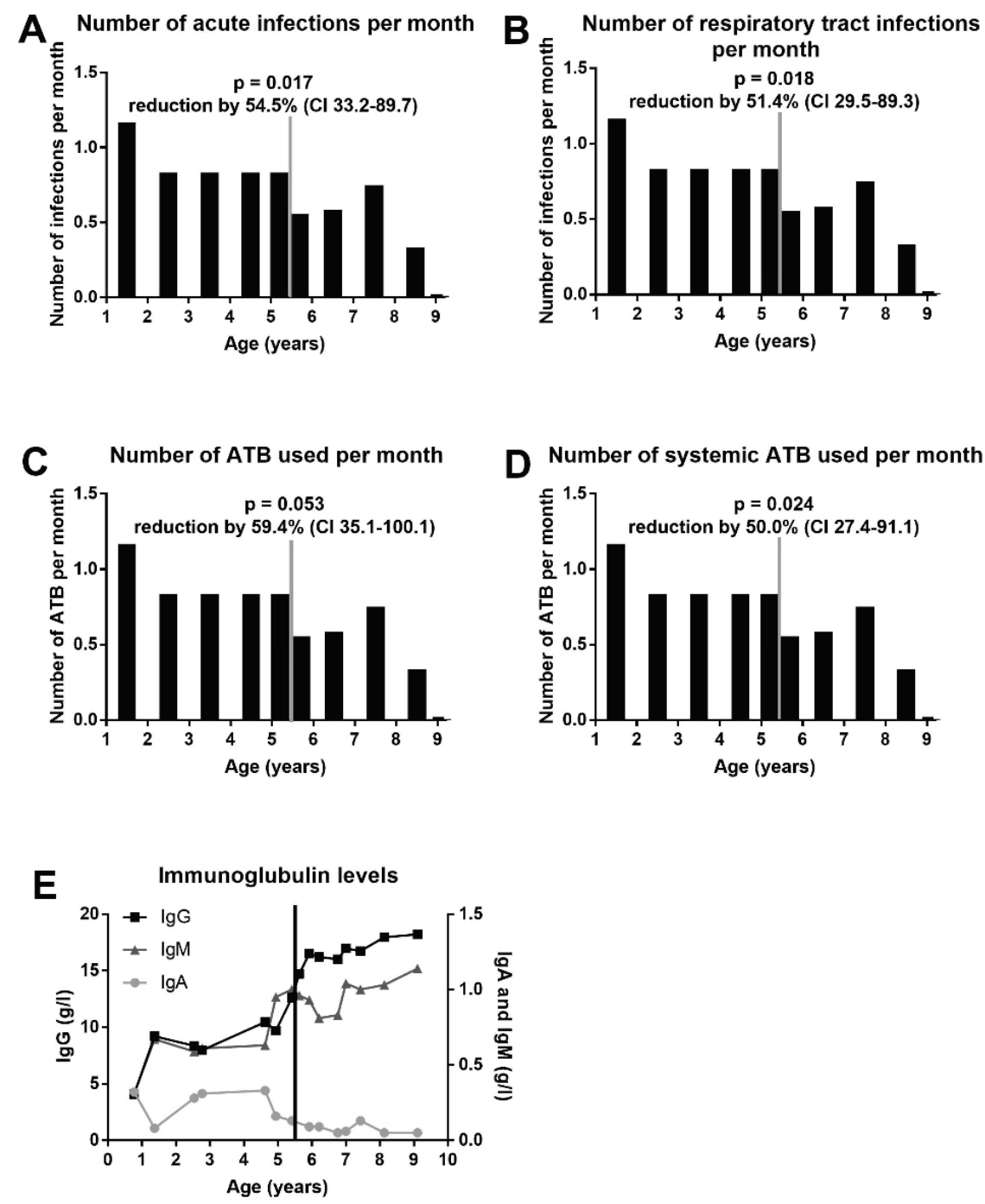

We interrupted the subcutaneous immunoglobulin therapy after 3.8 years at the age of 9.2 years, as we thought that the risk for acute infections has decreased (age $>6$ years). The effect of immunoglobulin treatment persisted also for the following 3 months, as the patient remained without any infection. However, subsequently he had several infections following each other during the period of 3 weeks requiring admitting to the hospital and a treatment with combination of intravenous antibiotics.

We have shown that our proband with MEHMO syndrome had normal $\operatorname{IgG}$ serum levels and partial abnormalities in the immune system, however, he had frequent acute infections and responded well to the treatment with immunoglobulins.

Our proband had the mutation of the EIF2S3 gene encoding the $\gamma$ subunit of eIF2 crucial for translation initiation. In agreement with this, we have previously shown that he had a deficiency of several peptide hormones (Skopkova et al. 2017, Stanik et al. 2018).
Fig. 1. Phenotype of the proband prior and on the immunoglobulin treatment. (A) Number of acute infections per month, (B) Number of acute respiratory tract infections per month, (C) Number of infections treated with antibiotics (ATB) per month, (D) Number of infections treated with systemic antibiotics per month, and (E) Immunoglobulin levels. The grey line symbolizes the start of immunoglobulin therapy. Differences between periods with and without immunoglobulin therapy were calculated by Poisson regression.
However, some serum protein concentrations were normal in this patient, e.g. albumin, IgG and IgM levels. Therefore, the frequent infections in proband were not caused by a severe deficiency of immunoglobulin production. However, the quality of antibodies synthesized adaptively on-demand in acute infections could be defective. The patient had a deficiency of peptide hormones synthesized on demand (Stanik et al. 2018) and presented with decreased B cell counts. We could speculate, that deficiency of specific antibodies could explain the increased frequency of acute infections despite normal total IgG and IgM serum levels. This theory supports the good response on the immunoglobulin treatment and severe infections 3 months after interrupting the immunoglobulin treatment. Another explanation could be decreased IgA levels, which should increase with age, although most people with IgA deficiency are asymptomatic. However, other regulatory or structural proteins of innate 
and adaptive immunity could also participate in frequent infection phenotype. Hypotonic muscles and decreased ability to expectorate may also partly explain frequent pneumonia, but it could not elucidate upper respiratory infection.

It is hard to compare our findings with previously reported patients with MEHMO, as the majority of other studies did not deal with the immune phenotype. Only Moortgat et al. (2016) reported on a patient with MEHMO, carrying the same mutation as our proband, who died of respiratory failure and multiple organ dysfunction syndrome. Among other syndromes involved in eIF2 function or regulation influencing the protein synthesis, recurrent infections were reported only in patients with Wolcott-Rallison syndrome with a mutation of the $E I F 2 A K 3$ gene encoding eIF2 alpha kinase (Julier and Nicolino 2010, Huang and Wei 2019). Similarly to MEHMO patients, serum immunoglobulin levels are in the normal range in people with WolcottRallison syndrome.

The major limitation is the impact of age on the frequency of acute infections - the younger children are more prone to infections, however, at least proband was treated excellently by his parents with very low microbial exposure. Also, his long-term stagnation in psychomotor development (corresponding to the age of 2-3 months) substantially decreased environmental exposures. Our patient is probably one of the longest surviving patient with this syndrome.

In conclusion, the defect in protein synthesis in MEHMO syndrome has a strong impact on several organs, potentially including the immune system. Our patient had frequent acute infections responding well to immunoglobulin treatment. Further case reports with more detailed analyses will be needed to confirm the benefit of immunoglobulin treatment in children with MEHMO syndrome.

\section{Conflict of Interest}

There is no conflict of interest.

\section{Acknowledgements}

We would like to acknowledge the attitude and cooperation of the parents of proband. This work was supported by research grants supported by the Slovak Research and Development Agency APVV-17-0296, the grant of the Slovak Ministry for Health 2019/20-LFUK-8, and Scientific Grant Agency of the Ministry of Education, Science, Research and Sport of the Slovak Republic and the Slovak Academy of Sciences 2/0083/17.

\section{References}

BOYLE JM, BUCKLEY RH: Population prevalence of diagnosed primary immunodeficiency diseases in the United States. J Clin Immunol 27: 497-502, 2007. https://doi.org/10.1007/s10875-007-9103-1

HUANG A, WEI H: Wolcott-Rallison syndrome due to the same mutation in EIF2AK3 (c.205G>T) in two unrelated families: A case report. Exp Ther Med 17: 2765-2768, 2019. https://doi.org/10.3892/etm.2019.7268

JULIER C, NICOLINO M: Wolcott-Rallison syndrome. Orphanet J Rare Dis 5: 29, 2010. https://doi.org/10.1186/1750$\underline{1172-5-29}$

MCCUSKER C, WARRINGTON R: Primary immunodeficiency. Allergy Asthma Clin Immunol 7 (Suppl 1): S11, 2011. https://doi.org/10.1186/1710-1492-7-S1-S11

MODELL V, KNAUS M, MODELL F, ROIFMAN C, ORANGE J, NOTARANGELO LD: Global overview of primary immunodeficiencies: a report from Jeffrey Modell Centers worldwide focused on diagnosis, treatment, and discovery. Immunol Res 60: 132-144, 2014. https://doi.org/10.1007/s12026-014-8498-Z

MOORTGAT S, DESIR J, BENOIT V, BOULANGER S, PENDEVILLE H, NASSOGNE MC, LEDERER D, MAYSTADT I: Two novel EIF2S3 mutations associated with syndromic intellectual disability with severe microcephaly, growth retardation, and epilepsy. Am J Med Genet A 170: 2927-2933, 2016. https://doi.org/10.1002/ajmg.a.37792

PAVITT GD, RON D: New insights into translational regulation in the endoplasmic reticulum unfolded protein response. Cold Spring Harb Perspect Biol 1: 4, 2012. https://doi.org/10.1101/cshperspect.a012278

SHEHATA N, PALDA V, BOWEN T, HADDAD E, ISSEKUTZ TB, MAZER B, SCHELLENBERG R, WARRINGTON R, EASTON D, ANDERSON D, HUME H: The use of immunoglobulin therapy for patients with primary immune deficiency: an evidence-based practice guideline. Transfus Med Rev 24 (Suppl 1): S28-S50, 2010. https://doi.org/10.1016/j.tmrv.2009.09.011 
SKOPKOVA M, HENNIG F, SHIN BS, TURNER CE, STANIKOVA D, BRENNEROVA K, STANIK J, FISCHER U, HENDEN L, MULLER U, STEINBERGER D, LESHINSKY-SILVER E, BOTTANI A, KURDIOVA T, UKROPEC J, NYITRAYOVA O, KOLNIKOVA M, KLIMES I, BORCK G, BAHLO M, ET AL.: EIF2S3 mutations associated with severe X-linked intellectual disability syndrome MEHMO. Hum Mutat 38: 409-425, 2017. https://doi.org/10.1002/humu.23170

STANIK J, SKOPKOVA M, STANIKOVA D, BRENNEROVA K, BARAK L, TICHA L, HORNOVA J, KLIMES I, GASPERIKOVA D: Neonatal hypoglycemia, early-onset diabetes and hypopituitarism due to the mutation in EIF2S3 gene causing MEHMO syndrome. Physiol Res 67: 331-337, 2018. https://doi.org/10.33549/physiolres.933689

STEINMULLER R, STEINBERGER D, MULLER U: MEHMO (mental retardation, epileptic seizures, hypogonadism and -genitalism, microcephaly, obesity), a novel syndrome: assignment of disease locus to xp21.1-p22.13. Eur J Hum Genet 6: 201-206, 1998. https://doi.org/10.1038/sj.ejhg.5200180

VOZEH F: Immunity - a significant pathogenic factor as well as an integral part of the psychoneuroendocrine-immune regulations. Physiol Res 67: 165-173, 2018. https://doi.org/10.33549/physiolres.933656

YOUNG-BAIRD SK, LOURENCO BERTOLESSI M, ELDER MK, KLANN E, LIEBAU S, DEVER TE: Suppression of MEHMO syndrome mutation in EIF2 by small molecule ISRIB. Mol Cell 77: 875-876, 2020. https://doi.org/10.1016/j.molcel.2019.11.008 